\title{
Synthesis, characterization, and cytocompatibility of potential cockle shell aragonite nanocrystals for osteoporosis therapy and hormonal delivery
}

This article was published in the following Dove Press journal:

Nanotechnology, Science and Applications

18 January 2017

Number of times this article has been viewed

\author{
Alhaji Zubair Jaji ${ }^{1,2}$ \\ Md Zuki Bin Abu Bakar ${ }^{1,3}$ \\ Rozi Mahmud ${ }^{4}$ \\ Mohamad Yusof Loqman ${ }^{5}$ \\ Mohamad Noor Mohamad \\ Hezmee \\ Tijani Isa ${ }^{3}$ \\ Fu Wenliang ${ }^{3}$ \\ Nahidah Ibrahim Hammadi' \\ 'Department of Veterinary Pre- \\ Clinical Science, Universiti Putra \\ Malaysia, Serdang, Selangor, Malaysia; \\ ${ }^{2}$ Department of Veterinary Anatomy, \\ Faculty of Veterinary Medicine, \\ University of Ilorin, Ilorin, Kwara, \\ Nigeria; ${ }^{3}$ Molecular Biomedicine \\ Laboratory, Institute of Bioscience, \\ Universiti Putra Malaysia, Serdang, \\ Selangor, Malaysia; ${ }^{4}$ Department of \\ Imaging, Faculty of Medicine and \\ Health Science, Universiti Putra \\ Malaysia, Serdang, Selangor, Malaysia; \\ ${ }^{5}$ Department of Companion Animal \\ Medicine and Surgery, Universiti Putra \\ Malaysia, Serdang, Selangor, Malaysia
}

Correspondence: Md Zuki Bin Abu Bakar Molecular Medicine Laboratory,

Institute of Bioscience, Universiti Putra

Malaysia, 43400 Serdang, Selangor,

Malaysia

Tel +60389462102

Fax +60 389472 I0I

Email zuki@upm.edu.my

\begin{abstract}
Calcium carbonate is a porous inorganic nanomaterial with huge potential in biomedical applications and controlled drug delivery. This study aimed at evaluating the physicochemical properties and in vitro efficacy and safety of cockle shell aragonite calcium carbonate nanocrystals (ANC) as a potential therapeutic and hormonal delivery vehicle for osteoporosis management. Free and human recombinant parathyroid hormone 1-34 (PTH 1-34)-loaded cockle shell aragonite calcium carbonate nanocrystals (PTH-ANC) were synthesized and evaluated using standard procedures. Transmission electron microscopy and field emission scanning electron microscopy results demonstrated highly homogenized sphericalshaped aragonite nanocrystals of $30 \pm 5 \mathrm{~nm}$ diameter. PTH-ANC had a zeta potential of $-27.6 \pm$ $8.9 \mathrm{mV}$. The encapsulation efficiency of the formulation was found to be directly proportional to the concentrations of the drug fed. The X-ray diffraction patterns revealed strong crystallizations with no positional change of peaks before and after PTH-ANC synthesis. Fourier transform infrared spectroscopy demonstrated no detectable interactions between micron-sized aragonite and surfactant at molecular level. PTH-ANC formulation was stabilized at $\mathrm{pH} 7.5$, enabling sustained slow release of PTH 1-34 for 168 h (1 week). A 3-(4,5-dimethylthiazol2-yl)-2,5-diphenyltetrazolium bromide cytocompatibility assay in Human Foetal Osteoblast Cell Line hFOB 1.19 showed that ANC can safely support osteoblast proliferation up to $48 \mathrm{~h}$ whereas PTH-ANC can safely support the proliferation at $72 \mathrm{~h}$ and beyond due to the sustained slow release of PTH 1-34. It was concluded that due to its biogenic nature, ANC is a cytocompatible antiosteoporotic agent. It doubles as a nanocarrier for the enhancement of efficacy and safety of the bone anabolic PTH 1-34. ANC is expected to reduce the cost, dosage, and dose frequency associated with the use of PTH 1-34 management of primary and secondary forms of osteoporosis.
\end{abstract}

Keywords: bone, FESEM, FT-IR, MTT viability, PTH 1-34, sustained release, TEM, XRD, zeta potential

\section{Introduction}

Bone undergoes continuous adjustments (remodeling) by resorption of old bones by osteoclast and formation of new bones by osteoblast. ${ }^{1}$ These activities are normally stable and under physical and hormonal control. Imbalances between osteoclast and osteoblast activities characterized by bone resorption at a level that exceeds the rate of bone formation have been found to be responsible for osteoporosis and its associated bone loss and skeletal fragility. ${ }^{2}$ Osteoporosis and its associated fractures have been predicted as a disease with potentials of increased public health importance in future generations, possibly due to increase in life expectancy. ${ }^{3}$ 
The recombinant human parathyroid hormone 1-34 (PTH 1-34) is commercially known as Teriparatide. Forteo is a 4117.8 Da peptide approved by the Food and Drug Administration as a therapeutic agent for osteoporosis. ${ }^{4} \mathrm{PTH}$ 1-34 is a potent bone anabolic that treats osteoporosis by prompting remodeling cascades in osteogenic cells through the stimulation of bone matrix production and suppression of osteoblast apoptosis. ${ }^{5,6}$ PTH 1-34 has a high absolute bioavailability, rapid absorption, and disposition after a single subcutaneous administration in healthy rats. It displayed a characteristic mono-exponential swift and substantial absorption and decline, with respective absolute bioavailability and elimination half-life of $65 \%$ and 3.4-4.1 h. Approximately $6 \%$ of the administered PTH 1-34 was excreted into bile for up to $24 \mathrm{~h}$ after administration, whereas $\sim 91 \%$ were recovered in urine and $2 \%$ were recovered from feces after $72 \mathrm{~h}$ of administration. ${ }^{7}$ Based on available data from 10, 20, and $40 \mu \mathrm{g}$ subcutaneous doses of PTH 1-34 in humans, it is concluded that the absolute bioavailability of PTH 1-34 is $\sim 95 \%$. PTH 1-34 has a rapid rate of absorption and elimination. It reaches peak serum concentrations in $30 \mathrm{~min}$ after subcutaneous administration of a $20 \mu \mathrm{g}$ dose and drops to an undetectable concentration within $3 \mathrm{~h}$. It has a distribution of $\sim 0.12 \mathrm{~L} / \mathrm{kg}$ after intravenous injection and a half-life in serum of $\sim 5$ min when injected intravenously and $\sim 1 \mathrm{~h}$ when administered by subcutaneous injection. ${ }^{8}$ Due to its short life and fast clearance, PTH 1-34 peptide is presently injected subcutaneously daily for 2 years. Thus, there is a pressing need to improve patient compliance through the reduction of frequency of injection or sorting for a feasible alternate route of administration that will prolong the time taken for the peptide to be exposed to serum. A PTH 1-34-loaded nanoformulation can enable sustained slow release of its anabolic dose and rule out possible side effects associated with its sudden exposure into patient's blood. ${ }^{9}$ Moreover, studies have shown that blood clearance of the smaller nanoparticles was twice as slow as those of larger nanoparticle formulations. ${ }^{10}$

Calcium is the fifth most abundant element in the body. It is an important structural component of bone and teeth and is also necessary for the normal functioning of all the muscles (skeletal, heart, and smooth muscles) and nerves as well as the normal clotting of blood. Prolonged, inadequate intake of calcium causes weak bones (osteoporosis). Products containing calcium carbonate $\left(\mathrm{CaCO}_{3}\right)$ are used to increase the intake of calcium in individuals whose diets are low in calcium. The National Institutes of Health recommend $1000-1500 \mathrm{mg}$ of calcium per day as part of regimen to prevent the loss of bone associated with aging. $\mathrm{CaCO}_{3}$ products contains $40 \%$ absorbable calcium. Therefore, a $1500 \mathrm{mg}$ tablet of $\mathrm{CaCO}_{3}$ provides $600 \mathrm{mg}$ of calcium. $\mathrm{CaCO}_{3}$ is also used as an antacid for treating stomach distress. ${ }^{11} \mathrm{CaCO}_{3}$ is a calcium salt found in limestone, chalk, marble, plant ashes, bones, many shelled mollusks, and coccolithophores. It is also obtained as a white precipitate by passing carbon dioxide into a suspension of calcium hydroxide in water. It is used in dentifrices and in pharmaceuticals as an antacid and to supplement bodily calcium stores. ${ }^{12,13}$ It has presently become popular in the field of nanotechnology as a highly biocompatible porous compound. It has an easily manipulative physicochemical properties, surface chemistry (shape and size), and method of production at a large scale. ${ }^{14}$ It is $\mathrm{pH}$ sensitive, and its solubility is exponentially and inversely proportional to its $\mathrm{pH} .{ }^{15}$ These make it a novel inorganic material with a huge potential in biomedical applications and controlled drug delivery. ${ }^{16}$

The cockle shell (Anadara granosa)-derived aragonite $\mathrm{CaCO}_{3}$ nanocrystals (ANC) is the chosen nanocarrier for this study. ANC is an inorganic nanocrystal synthesized using the top-down approach of nanoparticle preparation. Cockles are dominant faunal bivalves present, sometimes comprising the entire bivalve fauna in deep shell beds on sandy mud flats in the upper parts of estuaries and harbors. They live in super abundance in the low tidal and shallow subtidal zones of most of our present-day estuaries and enclosed bays and harbors. ${ }^{17}$ In Malaysia, the cockle shells (A. granosa) are cultivated in a large scale in the area of intertidal coastal bordering mudfield regions and in many parts of South East Asian countries, mainly Thailand and Indonesia. They are by far the most vital species cultured in Malaysia. ${ }^{18}$ The cockle shells contain $>98 \%$ of $\mathrm{CaCO}_{3}$ and thus has the potential for the development of biomaterials for orthopedic applications. ${ }^{19}$

Aragonite $\mathrm{CaCO}_{3}$ polymorph is a thermodynamically less stable and less available form of crystalline $\mathrm{CaCO}_{3}$ synthesized in laboratory. The size and shape of aragonite are strongly dependent on the preparation methods and conditions..$^{20}$ Due to the huge striking properties of aragonite nanoparticles as a material of biomedical importance, researchers have paid huge attention in the invention of methods for controlled and facile synthesis of aragonite nanoparticles of appropriate sizes and shapes using bottom-up methods. ${ }^{21,22}$ Yet, none of these methods can promise the production of pure aragonite nanoparticles of suitable sizes and shapes. Aragonite resulting from these methods of production is often mixed with calcite ${ }^{21}$ or calcite and vaterite. ${ }^{23}$ Therefore, these methods may not be appropriate for specific biomedical applications. Though carbonation methods are found to be useful in industries 
and environmentally friendly, they are associated with the need for strict control of temperature, purified raw materials, and strenuous gas $\left(\mathrm{CO}_{2}\right.$ or combination of $\mathrm{CO}_{2}$ and $\left.\mathrm{N}_{2}\right)$ bubbling phases which are complicated, expensive, and timeconsuming. ${ }^{24}$ Other impurities such as BS-12 are also added to the final products. ${ }^{24}$ Therefore, the top-down approach of ANC synthesis from its natural sources, for example, cockle shells or sea shells is greatly promising. ${ }^{25}$

This study is in line with the global efforts at tackling the menace of osteoporosis and its associated complications. It aimed at synthesis, physicochemical characterizations, and in vitro evaluation of the ANC as a potential therapeutic and nanocarrier for sustained slow release of anabolic antiosteoporotic PTH 1-34. The PTH 1-34-loaded cockle shell aragonite calcium carbonate nanocrystals (PTH-ANC) will result in reducing dosage, cost, side effect, and dosing frequency of PTH 1-34, toward an effective management of primary and secondary forms of osteoporosis and better compliance from patients.

\section{Materials and methods}

\section{Preparation of PTH I-34-loaded cockle} shell aragonite calcium carbonate nanocrystals (PTH-ANC)

\section{Preparation of micron-sized aragonite $\mathrm{CaCO}_{3}(\mathrm{MAC})$ powder}

MAC preparation entailed scrubbing of dirt and tissues from $\sim 250 \mathrm{~g}$ of the cockle shells. The cleaned shells were boiled for $10 \mathrm{~min}$ and then cooled to room temperature. The shells were thoroughly washed with distilled water and then oven-dried in Memmert UM500 oven (GmbH Co, Schwabach, Germany) at $50^{\circ} \mathrm{C}$ for 7 days. The shells were then powdered with mortar and pestle (Agate Top diameter $90 \mathrm{~mm}$ ), finely ground with a stainless steel blender (Blendor ${ }^{\circledR}$; HCB 550, Stamford, CT, USA), and sieved using a $75 \mu \mathrm{m}$ aperture-sized stainless steel laboratory test sieve (Endecott Ltd., London, UK) to get 75 $\mu \mathrm{m}$ diameter-sized particles. The coarse unfiltered remnants were further dried in oven for $10 \mathrm{~h}$, ground with mortar and pestle, blended and sieved to further reduce their diameter. The micron-sized cockle shell powder thus produced was further desiccated in an oven at $50^{\circ} \mathrm{C}$ for a 7 days duration for complete dry up. The MAC was then packaged in a JP Packaging polyethylene plastic bag.

\section{Preparation of spherical-shaped aragonite $\mathrm{CaCO}_{3}$ nanocrystals (ANC)}

Approximately $2 \mathrm{~g}$ of the $75-\mu \mathrm{m}$-sized powder was placed in a 100-mL flat-bottomed flask, mixed with $50 \mathrm{~mL}$ of high performance liquid chromatography (HPLC)-grade (resistance
$>18 \mathrm{M} \mathrm{cm}$ ), produced by a Milli-RO6 plus Milli-Q-Water System (Organex, São Paulo, Brazil). Approximately 0.5 $\mathrm{mL}$ of dodecyl dimethyl betaine (BS-12) (Sigma Aldrich, St Louis, MO, USA) was then added to each flask and stirred vigorously at $1000 \mathrm{rpm}$ in room temperature for $90 \mathrm{~min}$ using a Systematic Multi-Hotplate stirrer (DH.WMH03506 DAIHAN WiseStir ${ }^{\circledR}$ Systematic Multi-Hotplate Stirrers, $3 \times 2$ Places, 6 Positions, South Korea) and a magnetic stirrer bar. The slurry obtained from this process was filtered and rinsed with 18.0-cm-sized double ring filter papers (Filtres Fioroni, Ingré, France). The final products were dried in Memmert UM500 oven ( $\mathrm{GmbH} \mathrm{Co}$ ) for $24 \mathrm{~h}$ at $100^{\circ} \mathrm{C}$ and packed in JP Packaging polyethylene plastic bags and stored in moisturefree enclosure (at $50^{\circ} \mathrm{C}$ ) for further analysis and usage.

\section{Synthesis of PTH-ANC}

PTH-ANC was synthesized by separately adding different concentrations $\left(1 \times 10^{-3}, 2 \times 10^{-3}\right.$, and $\left.4 \times 10^{-3} \mathrm{mg} / \mathrm{mL}\right)$ of aqueous solutions of PTH 1-34 into $10 \mathrm{~mL}$ cockle shell aragonite $\mathrm{CaCO}_{3}$ nanocrystal (ANC) suspensions of $0.1 \%$ $(\mathrm{w} / \mathrm{v})$ concentration. This research was aimed at studying the drug content and encapsulation efficiency of ANC. The encapsulations of PTH 1-34 in $\mathrm{CaCO}_{3}$ nanocrystals were achieved by incubating the resulting solutions overnight at $4^{\circ} \mathrm{C}$ under constant stirring. The PTH-ANC suspensions obtained were centrifuged at $10,000 \times g$ for $10 \mathrm{~min}$, and the pelleted nanocrystals were steadily dried at $4^{\circ} \mathrm{C}$.

\section{Drug content and encapsulation efficiency of ANC}

The amount of PTH 1-34 in solution was measured using Human PTH 1-34 Enzyme Immunoassay kit (EK-055-08, Phoenix Pharmaceuticals Company Inc., Karlsruhe, Germany) protocols. The immunoplate in this kit was precoated with secondary antibody with blocked nonspecific binding sites. A standard curve of known concentration was established (Figure S1) and unknown concentrations in samples were calculated using the equation of the curve. The drug content and drug encapsulation efficiency were calculated using Equations 1 and 2 as adopted from Rajat et al. ${ }^{26}$

$$
\text { Drug content }(\%)=\frac{\mathrm{tdf}-\mathrm{fd}}{\mathrm{wnr}} \times 100
$$

$$
\text { Drug encapsulation efficiency }(\%)=\frac{\mathrm{tdf}-\mathrm{fd}}{\mathrm{tdf}} \times 100
$$

where tdf refers to the total drug fed to the formulation, fd refers to the free drug, and wnr refers to the weight of nanocrystals recovered from the formulation. 


\section{Physicochemical characterization of ANC and PTH-ANC}

Transmission electron microscopy (TEM)

The TEM (Hitachi H-7100; Hitachi Ltd., Tokyo, Japan) was used to determine the shape and size of ANC. Sample preparation for TEM entailed dispersal of a pinch of ANC powder in $100 \%$ acetone, followed by ultra-sonication (Power Sonic 505; Gangnam-gu, South Korea) for $30 \mathrm{~min}$. A drop of the supernatant was then placed onto a carbon-cover copper grids placed on a filter paper and left to dry at room temperature. The TEM measurement was made at $150 \mathrm{kV}$.

\section{Field emission scanning electron microscopy (FESEM)}

The FESESM (JEOL 7600F; JEOL, München, Germany) $\mathrm{GmbH}$ was used to evaluate homogeneity and further evaluate the shape and size of ANC. Sample preparation for FESEM entailed dispersal of a light pinch of ANC powder on adhesive-coated metallic stub. The so-prepared stub was then installed into the FESEM microscope and the microscopy measured.

\section{Zeta potential}

Pelleted PTH-ANC was resuspended in deionized water. The mean zeta potential of the PTH-ANC was based on dynamic light scattering determined by photon correlation spectroscopy using Zetasizer (Ver. 6.12, Serial Number: MAL1042820; Malvern Instruments Ltd., Malvern, UK).

\section{Fourier transform infrared (FT-IR)} spectrophotometry

The FT-IR spectrophotometer (Model 100 series; Perkin Elmer) was used to analyze the chemical properties of PTH I-34, PTH-ANC, ANC, and MAC over a range of 4000 to $280 \mathrm{~cm}^{-1}$ at a $2 \mathrm{~cm}^{-1}$ resolution and averaging 64 scans.

\section{X-ray powder diffraction (XRD)}

In this study, the composition, purity, and crystallinity of PTH I-34, PTH-ANC, ANC, and MAC were studied by an X-ray powder diffractometer (Shimadzu XRD-6000 powder diffractometer with $\mathrm{CuK} \alpha[\lambda=1.540562 \AA]$ at $40 \mathrm{kV}$ and 30 $\mathrm{mA}$ ). A standard back fill method was used in preparation of samples for XRD. This entailed packing $\sim 0.35 \mathrm{~g}$ of powder into the holder for a $90^{\circ}$ tilt test. The holder was sufficiently firm enough to prevent the sample from falling out during the test. The crystallinity phases were determined with diffraction angles from $20^{\circ}$ to $70^{\circ}$ at $37^{\circ} \mathrm{C}$.

\section{Drug release profile of PTH-ANC}

The release profile of PTH-ANC was determined at $\mathrm{pH} 7.5$ within a span of $168 \mathrm{~h}$. This entailed centrifuging of PTHANC suspension at 20,000 rpm for $45 \mathrm{~min}$ and the pellet thereby obtained was dispersed in $10 \mathrm{~mL}$ of phosphatebuffered saline solution of $\mathrm{pH} 7.5$ with a final concentration of $2.5 \times 10^{-3} \mathrm{mg} / \mathrm{mL}$. Entire volume obtained was divided equally into the required number of Eppendorf tubes for the time-specific release study at time intervals $0,0.5,1,3,6,9$, $12,24,48,72,96,120,144$, and $168 \mathrm{~h}$. Tubes were incubated at $37^{\circ} \mathrm{C}$ under gentle shaking in the YIH DER orbital shaker incubator TU-400. At appropriate time intervals, the contents of the Eppendorf tubes were centrifuged, and PTH 1-34 released from PTH-ANC was later quantified using Human PTH 1-34 Enzyme Immunoassay (EK-055-08; Phoenix Pharmaceuticals Company Inc., Karlsruhe, Germany). The percentage of PTH 1-34 peptide released was calculated based on the ratio of the amount of peptide released at a given time to the amount loaded in the formulation, as below:

$$
\begin{aligned}
& \% \text { of PTH 1-34 released }= \\
& \frac{\text { Quantity of PTH 1-34 released at time "t" }}{\text { Quantity of PTH 1-34 loaded in the formulation }}
\end{aligned}
$$

The percentage of PTH 1-34 peptide released was plotted against each time period to obtain a cumulative graph depicting the release profile.

\section{Cell culture}

The hFOB 1.19 (ATCC ${ }^{\circledR}$ CRL11372 ${ }^{\text {TM }}$ ) cell line was cultured in $5 \% \mathrm{CO}_{2}$ in air atmosphere incubator, Sanyo inCu safe incubator (Sanyo MCO-18AIC (UV); Osaka, Japan), at $34^{\circ} \mathrm{C}$ using a T75 culture flask in Ham's F12 Medium Dulbecco's Modified Eagle's Medium, with $2.5 \mathrm{mM}$ L-glutamine (without phenol red) and $100 \mu \mathrm{g} / \mathrm{mL}$ each of penicillin and streptomycin.

The total viable cell population and seeding rate were calculated as below:

$$
\begin{aligned}
\text { Average live cells } & =\frac{\text { sum of live cells counted from chambers }}{\text { number of chambers counted }} \\
& =\frac{38+36+40+42}{4}=\frac{156}{4} \\
& =39
\end{aligned}
$$

Average dead cells $=\frac{\text { sum of dead cells counted from chambers }}{\text { number of chambers counted }}$

$$
\begin{aligned}
& =\frac{5+4+4+3}{4}=\frac{16}{4} \\
& =4
\end{aligned}
$$


Viability $(\%)=\frac{\text { number of live cells }}{\text { number of live }+ \text { dead cells }} \times 100$

$$
\begin{aligned}
& =\frac{39}{43} \times 100 \\
& =91 \%
\end{aligned}
$$

Cell density $($ cells $/ \mathrm{mL})=\frac{\text { average live cells } \times \text { dilution factor }}{\text { volume of a square }(\mathrm{mL})}$

$$
\begin{aligned}
& =\frac{\text { average live cells } \times \text { dilution factor }}{0.0001 \mathrm{~mL}} \\
& =\frac{39 \times 2}{0.0001} \\
& =780,000 \mathrm{cel} 1 \mathrm{~mL}
\end{aligned}
$$

Total cells $=$ cell density $\times$ volume of cell suspension

$$
\begin{aligned}
& =580,000 \times 4 \\
& =3,900,000 \text { cells } \\
& =3.9 \times 10^{6} \text { cells }
\end{aligned}
$$

\section{MTT relative proliferation assay}

A 72-h MTT viability of hFOB 1.19 (ATCC ${ }^{\circledR}$ CRL11372 $^{\text {TM}}$ ) due to effects of PTH 1-34, ANC, and PTH-ANC was assayed using the calculated total viable cell population and the final required volume. Approximately $100 \mu \mathrm{L}$ cell suspensions, each containing 10,000 cells were seeded per well in the 96-well Greiner flat-bottomed well plates. Cells were then incubated for 24-72 h.

During each experiment, the media were removed and the cells were cultured with $100 \mu \mathrm{L}$ of different concentrations of PTH 1-34, ANC, and PTH-ANC (20, 10, 5, 2.5, and $0 \mu \mathrm{g} / \mathrm{mL}$ ). The experiment was conducted in triplicates, and the optical densities were measured at $570 \mathrm{~nm}$.

\section{Results}

\section{Drug content and encapsulation efficiency of ANC}

Table 1 shows the PTH 1-34 content and encapsulation of ANC from three formulations. It was observed that the drug content and encapsulation efficiency were directly proportional to the amount of drug fed into the formulation.

Table I Drug loading concentrations, drug contents, and encapsulation efficiencies of PTH-ANC

\begin{tabular}{lllll}
\hline Samples & $\begin{array}{l}\text { Weight of } \\
\text { ANC (mg) }\end{array}$ & $\begin{array}{l}\text { Weight of PTH I-34 } \\
\text { PTH I-34 } \\
\text { (mg) }\end{array}$ & $\begin{array}{l}\text { Encapsulation } \\
\text { content (\%) }\end{array}$ \\
\hline PTH-ANC $_{(1)}$ & 10 & 0.04 & 0.39 & 97.83 \\
PTH-ANC $_{(2)}$ & 10 & 0.02 & 0.19 & 94.45 \\
PTH-ANC $_{(3)}$ & 10 & 0.01 & 0.09 & 85.2 \\
\hline
\end{tabular}

Abbreviations: ANC, aragonite calcium carbonate nanocrystals; PTH I-34 parathyroid hormone I-34; PTH-ANC, PTH I-34-loaded cockle shell aragonite calcium carbonate nanocrystals.

\section{Physicochemical characterization of ANC and PTH-ANC \\ TEM}

Figure 1 shows the shape and size of ANC as viewed under transmission electron microscope. The micrograph images at lower magnification revealed the spherical-shaped nanocrystals of $30 \pm 5 \mathrm{~nm}$ diameter in size.

\section{FESEM}

Figure 2 shows the shape and size of ANC as viewed under field emission scanning electron microscope. The spherical particles were fairly uniform in size and $30 \pm 5 \mathrm{~nm}$ in diameter.

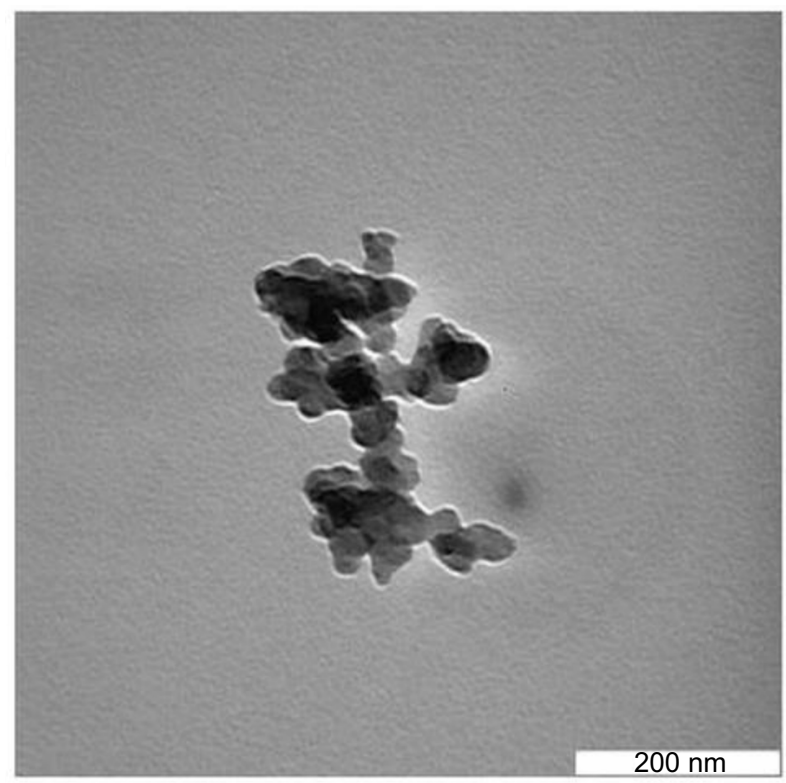

Figure I Transmission electron micrographs of the $30 \pm 5 \mathrm{~mm}$-sized spherical crystals of ANC.

Abbreviation: ANC, aragonite calcium carbonate nanocrystals.

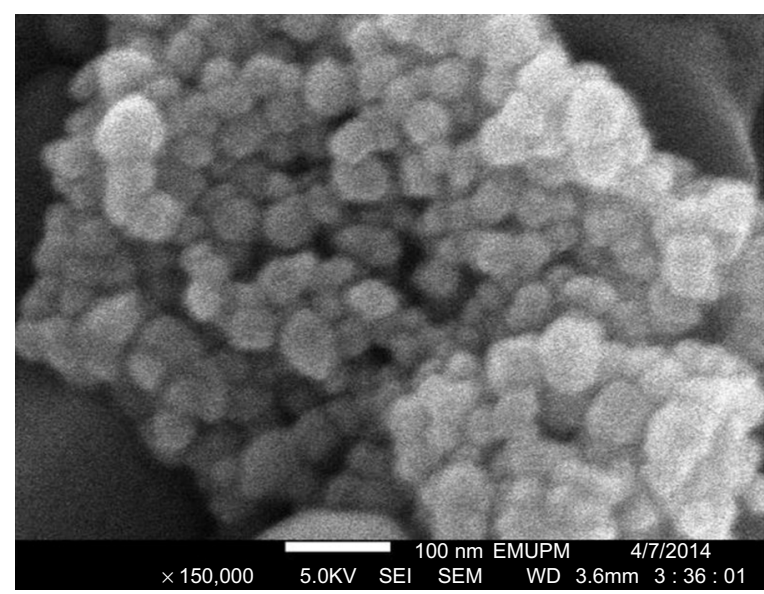

Figure 2 Field emission scanning electron micrograph of $30 \pm 5 \mathrm{~mm}$-sized spherical crystals of ANC.

Abbreviations: ANC, aragonite calcium carbonate nanocrystals; EMUPM, Universiti Putra Malaysia electron microscopy; SEl, secondary electron imaging; SEM, scanning electron microscopy; WD widest distance. 


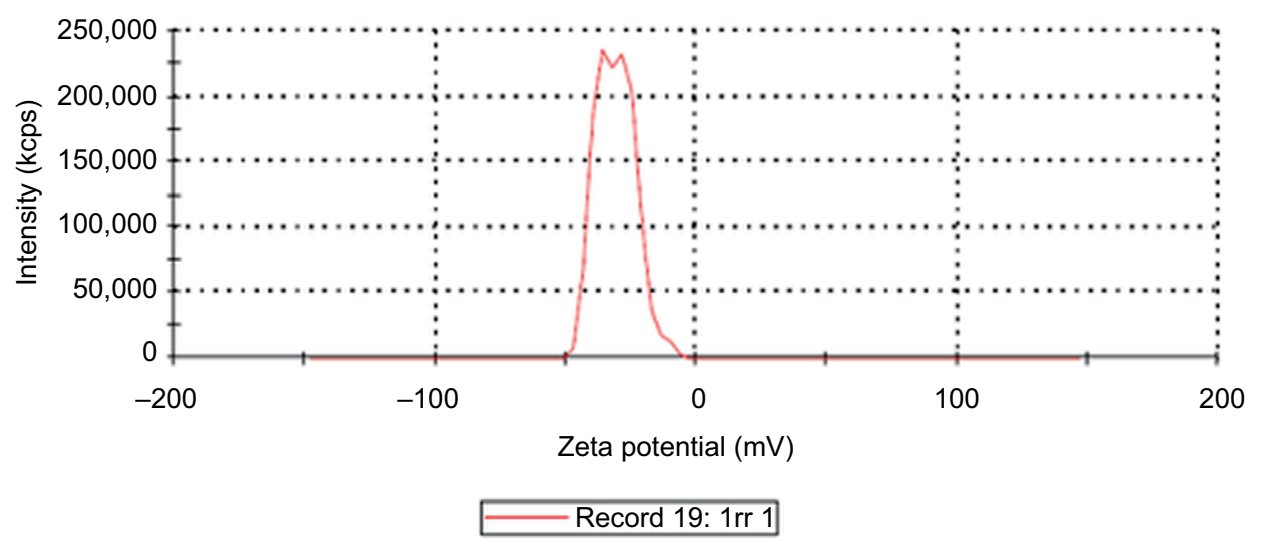

Figure 3 Zeta potential distribution of PTH-ANC.

Abbreviation: PTH-ANC, parathyroid hormone I-34 (PTH I-34)-loaded cockle shell aragonite calcium carbonate nanocrystals.

\section{Zeta potential}

Figure 3 shows the zeta potential distribution of PTH-ANC. The product was found to have a zeta potential of $-27.6 \pm$ $8.9 \mathrm{mV}$.

\section{FT-IR spectra}

Figure 4 compares the FT-IR spectra of PTH 1-34, PTHANC, ANC, and MAC. The spectra were composed of bands ranged from 4000 to $280 \mathrm{~cm}^{-1}$. Most of the peaks of the four products matched with one another, meaning that the purity of the MAC is not affected by the top-down method of ANC synthesis using BS-12 and that PTH 1-34 is well conjugated with ANC, forming PTH-ANC. The carbonate absorption peaks $\left(1449,1083,857\right.$, and $\left.714 \mathrm{~cm}^{-1}\right)$ were

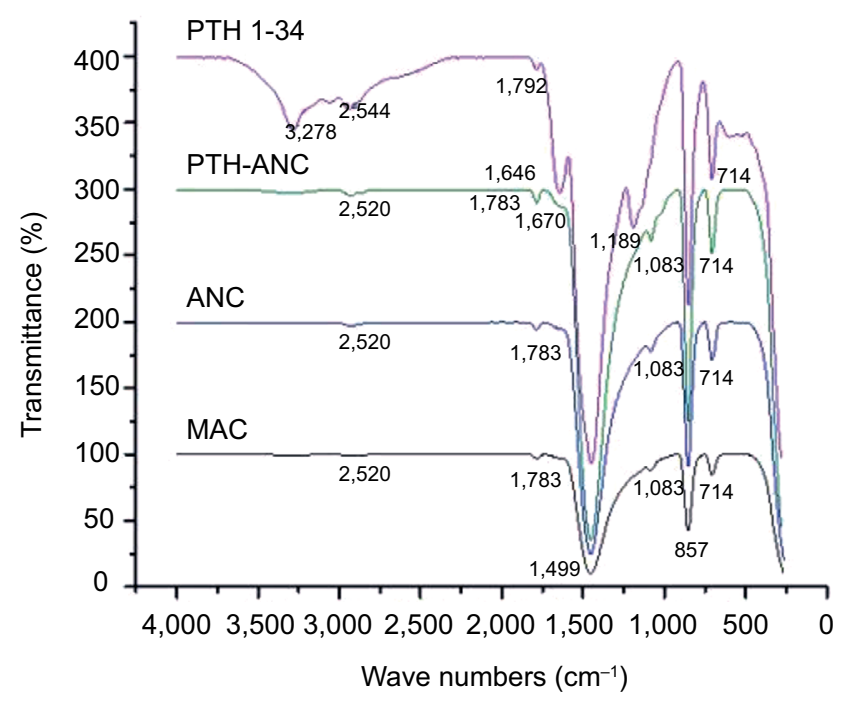

Figure 4 FT-IR spectra of PTH I-34, PTH-ANC, MAC, and ANC depicting how their absorption peaks matched.

Abbreviations: ANC, aragonite calcium carbonate nanocrystals; FT-IR, Fourier transform infrared; MAC, micron-sized aragonite $\mathrm{CaCO}_{3}$; PTH I-34, parathyroid hormone I-34; PTH-ANC, PTH I-34-loaded cockle shell aragonite calcium carbonate nanocrystals. clearly obvious in the MAC, ANC, and PTH-ANC spectra patterns.

\section{XRD}

Figure 5 shows that the XRD absorption peaks in the PTHANC, ANC, and MAC matched with one another. This means that the crystalline quality of aragonite $\mathrm{CaCO}_{3}$ in these powders is maintained throughout the process of PTH-ANC production.

\section{Drug release profile of PTH-ANC}

Figure 6 and Table S1 depict PTH 1-34 release profile from PTH-ANC. They depict the cumulative PTH 1-34 released from $2.5 \mathrm{mg}$ PTH-ANC (containing $9.8 \mu \mathrm{g}$ PTH 1-34) over a week $(168 \mathrm{~h})$ period at $\mathrm{pH} 7.5$, as quantified with the Human PTH 1-34 Enzyme Immunoassay (EK-055-08; Phoenix Phar-

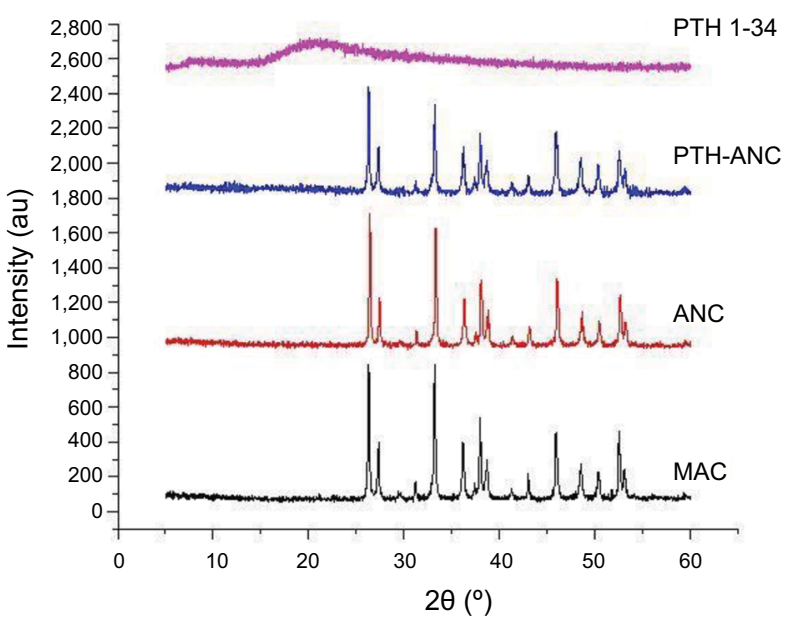

Figure 5 XRD spectra showing crystalline phases and qualities of PTH I-34, PTHANC, ANC, and MAC.

Note: The absorption peaks matched with one another.

Abbreviations: ANC, aragonite calcium carbonate nanocrystals; MAC, micron-sized aragonite $\mathrm{CaCO}_{3}$; PTH I-34, parathyroid hormone I-34; PTH-ANC, PTH I-34-loaded cockle shell aragonite calcium carbonate nanocrystals; XRD, X-ray diffraction. 


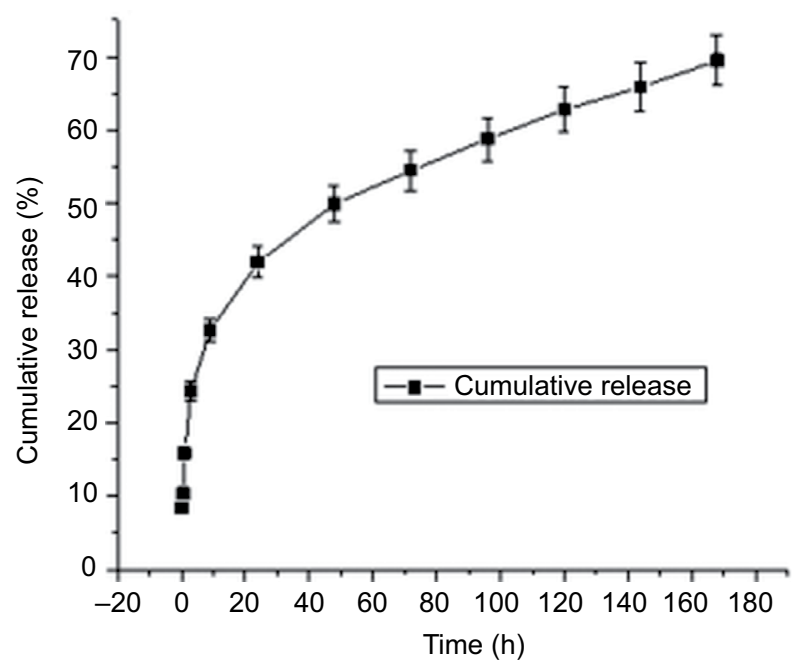

Figure 6 Cumulative PTH I-34 release from PTH-ANC at pH 7.5 over 168-h period.

Abbreviations: PTH I-34, parathyroid hormone I-34; PTH-ANC, PTH I-34-loaded cockle shell aragonite calcium carbonate nanocrystals; $h$, hours.

maceuticals Company Inc., Karlsruhe, Germany). The release profile was characterized by an initial burst release at $0 \mathrm{~h}$ followed by a marked decline at $0.5 \mathrm{~h}$ and steady rise to attain a highest peak by $24 \mathrm{~h}$. It was then sustained for the remaining period of the release.

\section{MTT relative proliferation assays}

Figure 7 depicts the $72 \mathrm{~h}$ MTT proliferation assays of PTH 1-34, ANC, and PTH-ANC at 20, 10, 5, 2.5, and $0 \mu \mathrm{g} / \mathrm{mL}$ on the hFOB 1.19 (ATCC ${ }^{\circledR}$ CRL11372 ${ }^{\mathrm{TM}}$ ) cell line. It was observed that relative to the control, all the three treatments supported the proliferation of the osteoblast cells at the said period in a concentration-dependent manner. Generally, ANC and PTH-ANC gave better performance in the 24- and 48-h periods. ANC had the best performance in the 24 and $48 \mathrm{~h}$, whereas PTH-ANC performed best at the 72-h period due to the sustained release of its encapsulated PTH 1-34.

\section{Discussion}

Physicochemical characterization and in vitro bioassays have been identified as essential parts of an ideal characterization plan of nanoparticles prior to biomedical applications. This is to fully understand their efficacy and safety, the other component being in vivo studies. ${ }^{27}$ Cockle shells are excellent sources of naturally purified aragonite polymorph of $\mathrm{CaCO}_{3}{ }^{25}$ Although $\mathrm{CaCO}_{3}$ is renowned for its multifaceted applicability in the fields of human endeavours, ${ }^{9,20,25,28-31}$ it is poised for greater advancement through nanotechnology. Nanotechnology offers numerous prospects and gains to medical research by making pharmaceuticals more effective. ${ }^{27}$ The nanotechnological top-down of synthesis ANC from this natural reservoir holds huge benefits. It enables obtaining aragonite crystals in their natural forms while retaining most of their special features. ${ }^{25,32}$ The method of ANC synthesis used in this study is an improvement over the Islam et al's ${ }^{32}$ top-down synthesis of $\mathrm{CaCO}_{3}$ nanoparticles, by reducing the volume of surfactant and quantity and size of MAC used per round of synthesis from $2 \mathrm{~mL}, 5 \mathrm{~g}$, and $90 \mu \mathrm{m}$ to 0.5 $\mathrm{mL}, 2 \mathrm{~g}$, and $75 \mu \mathrm{m}$, respectively, while maintaining other parameters therein (stirring speed, time, and temperature). This enhanced the homogeneity and overall quality and

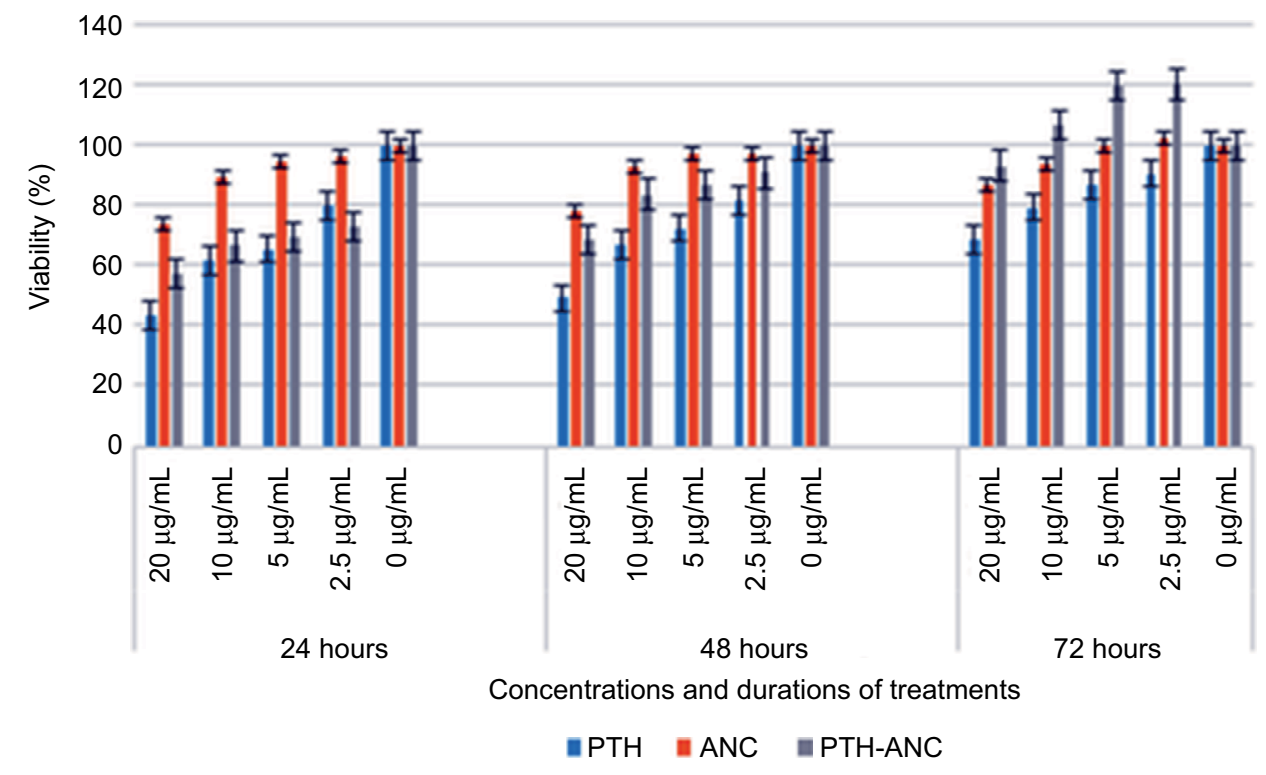

Figure 7 72-h MTT proliferation assay of PTH I-34, ANC, and PTH-ANC on the hFOB I.19 (ATCC ${ }^{\circledR}$ CRLII $372^{\text {TM }}$ ) cell line.

Abbreviations: PTH I-34, parathyroid hormone I-34; PTH-ANC, PTH I-34-loaded cockle shell aragonite calcium carbonate nanocrystals; h, hours. 
safety of the synthesized crystals for biological applications, while improving its environmental friendliness and low-cost features. Although surfactant inclusions in nanoformulations promote the dispersion of nanoparticles, they also interfere with conventional characterization methods and cause ambiguity in analytical results. They thus hamper the standardization of characterization techniques and clinical application of nanoparticles. ${ }^{27}$ The modified technique thus enabled the synthesis of highly homogenized spherical shape ANC of $30 \pm 5 \mathrm{~nm}$ size, as determined by TEM and FESEM. This size concurs with the size of $\mathrm{CaCO}_{3}$ synthesized by Islam et $\mathrm{al}^{32}$ and smaller than that of Kamba et $\mathrm{al}^{33}$ using the homogenizer method. The size fell within the range of sizes ideal for drug delivery. The $-27.6 \pm 8.9 \mathrm{mV}$ zeta potential obtained from this present study is an improvement over those earlier workers, due to its incorporated PTH 1-34. Although morphology, structure, surface area, size, oil adsorption, and chemical purity are important determinant factors for the use of $\mathrm{CaCO}_{3}$ in varying applications, morphology seems to be more important. As such, synthesis of $\mathrm{CaCO}_{3}$ crystals with homogenous shape and size is now a topic of research due to the interesting mechanical and optical properties. ${ }^{34-37}$

The loading content of PTH 1-34 and the encapsulation efficiency of ANC in the PTH-ANC composition were directly proportional to the concentrations of the drug fed. The formulations used have a loading content of $0.09 \%$, $0.19 \%$, and $0.39 \%$ and encapsulation efficiency of $85.2 \%$, $94.45 \%$, and $97.83 \%$ after $10 \mathrm{mg}$ of ANC was separately loaded with $0.01,0.02$, and $0.03 \mathrm{mg}$ of PTH 1-34. Calcium carbonate nanocrystals have been observed to contain surface pores (nanopores) that enable them load drugs or macromolecules by capillary force, irrespective of their surface charge and hydrophilicity. ${ }^{38-40}$

The FTIR spectra of PTH 1-34, MAC, ANC, and PTHANC were composed of bands ranging from 4000 to 280 $\mathrm{cm}^{-1}$. FTIR spectroscopy is a precise technique for identifying diverse phases of organic and inorganic compounds. It is a useful instrument for characterizing $\mathrm{CaCO}_{3}$ phases based on dissimilarities in their constituent carbonate ions. Carbonate ions and alike molecules, normally have four $\left(\mathrm{v}_{1}\right.$ to $\left.\mathrm{v}_{4}\right)$ vibrational peak modes: symmetric stretching, out-of-plane bending, doubly degenerate planar asymmetric stretching, and doubly degenerate planar bending. ${ }^{39}$ The observed absorption peaks in this study $\left(1449,1083,857\right.$, and $\left.714 \mathrm{~cm}^{-1}\right)$ fell within the ranges that were earlier described as characteristic peaks for carbonates in $\mathrm{CaCO}_{3}{ }^{41}$ and correspond to the $\mathrm{v}_{1}$ to $\mathrm{v}_{4}$ vibrations with some structural changes. These changes are attributed to the shift of the carbonate vibration mode in the milieu of oxygen atoms and the associated modification of the electrostatic valence of the $\mathrm{Ca}-\mathrm{O}$ bond. ${ }^{41-43}$ Similar peaks were reported by Raju et al, ${ }^{41}$ Islam et $a l,{ }^{25,32}$ and Kamba et al. ${ }^{33}$ The peak at $1083 \mathrm{~cm}^{-1}$ is the only characteristic aragonite phase of $\mathrm{CaCO}_{3}$ spectrum, whose carbonate ions are indiscernible in the infrared region. ${ }^{33,41}$ The absorption peaks in MAC correspond to those of ANC. The PTH 1-34 loading in ANC was established by sharp peaks at 1670 , $1449,1083,857$, and $714 \mathrm{~cm}^{-1}$ of ANC in accommodating the amine component of the PTH 1-34 absorption peaks in the formation of PTH-ANC. In the same vein, a sharp peak was observed at $2520 \mathrm{~cm}^{-1}$ of ANC in accommodating the carboxyl component of the PTH 1-34 absorption peaks.

$\mathrm{XRD}$ is a sensitive test that is used for the recognition of crystalline phases of inorganic compounds. XRD absorption peaks in PTH-ANC, ANC, and MAC matched with one another without positional shift. Two prominent peaks were found each for MAC, ANC, and PTH-ANC spectra. The first set of peaks were within $2 \theta=26.3^{\circ}$ and $26.4^{\circ}$ while the second set were within $2 \theta=33.2^{\circ}$ and $33.3^{\circ}$. This means that the crystalline quality of MAC and ANC is maintained throughout the process of PTH-ANC production.

This study presents cumulative PTH 1-34 released from $2.5 \mathrm{mg}$ PTH-ANC (containing $9.8 \mu \mathrm{g}$ of PTH 1-34) over a week $(168 \mathrm{~h})$ period at $\mathrm{pH}$ 7.5. Recent decades have witnessed speedy advancement in the area of drug delivery, with emphasis on sustained release systems, the main purpose of which is to maintain a given concentration of drug locally or systemically for a desired duration of time. ${ }^{44,45}$ An initial burst release of $8.37 \%$ of the total released drug was released at $0 \mathrm{~h}$ followed by a marked decline at $0.5 \mathrm{~h}$ and steady rise to attain a highest peak by $24 \mathrm{~h}$. It was then sustained for the remaining period of the release. A similar pattern of PTH 1-34 release was observed by Narayanan et $\mathrm{al}^{46}$ and Eswaramoorthy et $\mathrm{al}^{47}$ in studies on PTH 1-34-loaded polymers. Drug release patterns have been observed to take two forms: a slow zero (first-order rate) or an initial swift dose that is followed by sustained slow zero release of incorporated drug. ${ }^{45}$

It was observed from this present study that relative to the control, cellular viabilities in the PTH 1-34, ANC-, and PTH-ANC-treated cells were inversely proportional to their concentrations during the incubation periods of 24,48 , and $72 \mathrm{~h}$. Generally, ANC and PTH-ANC sustained better proliferations in the 24 and $48 \mathrm{~h}$ periods. PTH 1-34 sustained better viability over PTH-ANC at a concentration of $2.5 \mathrm{mg} / \mathrm{mL}$ in the $24 \mathrm{~h}$ period. ANC-treated wells had best viability of cells during the 24 and $48 \mathrm{~h}$ periods, whereas PTH-ANC sustained best viability at the $72 \mathrm{~h}$ period. This shows the 
dual potential of ANC as a bone anabolic and a nanocarrier for sustained release of PTH 1-34. The cockle shell-derived $\mathrm{CaCO}_{3}$ nanocrystal is a facilitator of osteoblast proliferation, differentiation, and adhesion. ${ }^{48}$ Tran and Webster ${ }^{49}$ observed an increase in cell viability without apparent toxicity from a similar research on pearl shell nanograde powder. Hydroxyapatite coated magnetic nanoparticles were also observed to cause increased osteoblast proliferation when compared to the uncoated form after 5 days of treatment. ${ }^{50}$

\section{Conclusion}

Conclusively, although earlier researchers do not consider the capability of $\mathrm{CaCO}_{3}$ as a nanocarrier for osteoporosis outcomes, the present study attests to the fact that ANC, just like other $\mathrm{CaCO}_{3}$ nanoparticles derived from shells, is a potential bone anabolic that can synergize with encapsulated antiosteoporotic agent for a cost-effective, safe, and better management of osteoporosis due to its biogenic nature.

\section{Disclosure}

The authors report no conflicts of interest in this work.

\section{References}

1. Cosman F, de Beur SJ, LeBoff MS, Lewiecki EM, Tanner B, Randall S, Lindsay R. Clinician's guide to prevention and treatment of osteoporosis. Osteoporos Int. 2014;25(10):2359-2381.

2. Kamel HK. Postmenopausal osteoporosis: etiology, current diagnostic strategies, and nonprescription interventions. J Manag Care Pharm. 2006;12(6 Suppl A):S4-S9; quiz S26-8.

3. Holroyd C, Cooper C, Dennison E. Epidemiology of osteoporosis. Best Pract Res Clin Endocrinol Metab. 2008;22(5):671-685.

4. Matthew S, Sharon B, Midura RJM. Parathyroid hormone suppresses osteoblast apoptosis by augmenting DNA repair. Bone. 2009; 45:590.

5. Lotinun S, Sibonga JD, Turner RT. Differential effects of intermittent and continuous administration of parathyroid hormone on bone histomorphometry and gene expression. Endocrine. 2002;17:29.

6. Jilka RL. Molecular and cellular mechanisms of the anabolic effect of intermittent PTH. Bone. 2007;40:1434.

7. Hu Z, Niu H, Yang X, Li H, Sang G, Li B. Recombinant human parathyroid hormone 1-34: pharmacokinetics, tissue distribution and excretion in rats. Int J Pharm. 2006;317(2):144-154.

8. Lily E. Medication guide Forteo teriparatide rDNA origin injection; 2010. Available from: http://pi.lilly.com/us/forteo-pi.pdf. Accessed March 16, 2016.

9. Naka K, Huang SC, Chujo Y. Formation of stable vaterite with poly(acrylic acid) by the delayed addition method. Langmuir. 2006;22:7760-7767.

10. Frank A, Eric P, Molnar LK, Omid CF. Factors affecting the clearance and biodistribution of polymeric nanoparticles. Mol. Pharmacol. 2008;5:505.

11. Omudhome O. Calcium Carbonate, Caltrate 600, Os-Cal 500, Tums Extra, Tums Chewy Delight, and Many Others. Medicinenet, Inc.; 2004. Available from: http://www.medicinenet.com/calcium_carbonate/ article.htm. Accessed March 29, 2016.

12. Merriam-Webster Online Medical Dictionary. An Encyclopedia Britannica Company. Available from: http://www.merriam-webster.com/ dictionary/calcium\%20carbonate. Accessed April 21, 2016.
13. Sugawara A, Ishii T, Kato T. Self-organized calcium carbonate with regular surface-relief structures. Angewandte Chemie. 2003;115(43):5457-5461.

14. Rodríguez R, Anna T, Jose M, et al. pH-responsive delivery of doxorubicin from citrate-apatite nanocrystals with tailored carbonate content. Langmuir. 2013;29:8213-8221.

15. Ming-Jium S, Chia-Yen H, Ling-Yi H, et al. Reversal of doxorubicinresistance by multifunctional nanoparticles in MCF-7/ADR cells. J Control Release. 2011;152(3):418-442.

16. Render D, Vijaya R, Khalda F, et al. Bio-based calcium carbonate nanoparticles for drug delivery applications. Int J Biomed Nanosci Nanotechnol. 2014;3:3.

17. Hayward BW. Kawerua mollusca. Tane. 1990;32:1.

18. Ibrahim N. Trace element content of Malaysian cockles (Anadara granosa). Food Chem. 1995;54(2):133-135.

19. Awang-Hazmi AJ, Zuki ABZ, Noordin MM, Jalila A, Norimah Y. Mineral composition of the cockle (Anadara granosa) shells of west coast of Peninsular Malaysia and its potential as biomaterial for use in bone repair. J Anim Vet Adv. 2007;6:591-594.

20. Wang LF, Sondi I, Matijevic E. Preparation of uniform needle-like aragonite particles by homogeneous precipitation. J Colloid Interface Sci. 1999;218(2):545-553.

21. Guo F, LiY, Xu H, Zhao G, He X. Size-controllable synthesis of calcium carbonate nanoparticles using aqueous foam films as templates. Mater Lett. 2007;61(27):4937-4939.

22. Wang C, Zhao J, Zhao X, Bala H, Wang Z. Synthesis of nanosized calcium carbonate (aragonite) via a polyacrylamide inducing process. Powder Technol. 2006;163(3):134-138.

23. Chen J, Xiang L. Controllable synthesis of calcium carbonate polymorphs at different temperatures. Powder Technol. 2009;189:64-69.

24. Wang C, Liu Y, Bala H, et al. Facile preparation of $\mathrm{CaCO} 3$ nanoparticles with self-dispersing properties in the presence of dodecyl dimethyl betaine. Colloids Surf A. 2007;297:179-182.

25. Islam KN, Zuki ABZ, Noordin MM, et al. Characterisation of calcium carbonate and its polymorphs from cockle shells (Anadara granosa). Powder Technol. 2011;213:188-191.

26. Rajat SM, Yasir SB, Mohd A. Formulation and evaluation of paclitaxel loaded PSA-PEG nanoparticles. J Appl Pharm Sci. 2011;1(5):96-98.

27. McNeil SE, editor. Characterization of Nanoparticles Intended for Drug Delivery, Methods in Molecular Biology. Series Volume 697. New York: Humana Press; 2011.

28. Colfen H, Mann S. Higher-order organization by mesoscale selfassembly and transformation of hybrid nanostructures. Angew Chem Int Ed Engl. 2003;42(21):2350-2365.

29. Dabbs DM, Aksay IA. Self-assembled ceramics produced by complexfluid templation. Annu Rev Phys Chem. 2000;51:601.

30. Mann S. Biomineralization: Principles and Concepts in Bioinorganic Materials Chemistry. Oxford: Oxford University Press; 2001:216 p.

31. McLeod MC, Gale WF, Roberts CB. Metallic nanoparticle production utilizing a supercritical carbon dioxide flow process. Langmuir. 2004;20:7078-7082.

32. Islam KN, Zakaria MZAB, Ali ME, Hussein MZ. Facile synthesis of calcium carbonate nanoparticles from cockle shells. J Nanomater. 2012; 2012:534010.

33. Kamba AS, Ismail M, Ibrahim TAT, Zuki ABZ. A pH-sensitive, biobased calcium carbonate aragonite nanocrystal as a novel anticancer delivery system. BioMed Res Int. 2013;2013:587451.

34. Loy JE, Guo JH, Severtson SJ. Role of adsorption fractionation in determining the $\mathrm{CaCO}_{3}$ scale inhibition performance of polydisperse sodium polyacrylate. Ind Eng Chem Res. 2004;43(8):1882-1887.

35. Xu AW, Antonietti M, Colfen H, Fang YP. Uniform hexagonal plates of vaterite $\mathrm{CaCO}_{3}$ mesocrystals formed by biomimetic mineralization. Adv Funct Mater. 2006;16:903-908.

36. Zhang CX, Zhang JL, Feng XY, et al. Influence of surfactants on the morphologies of $\mathrm{CaCO} 3$ by carbonation route with compressed $\mathrm{CO} 2$. Colloids Surf A. 2008;324:167-170.

37. Zhang Q, Ren L, Sheng Y, Ji Y, Fu J. Control of morphologies and polymorphs of $\mathrm{CaCO}_{3}$ via multi-additives system. Mater Chem Phys. 2010;122:156-163. 
38. Zhao Q, Han B, Wang, Z, et al. Hollow chitosan-alginate multilayer microcapsules as drug delivery vehicle: doxorubicin loading and in vitro and in vivo studies. Nanomed Nanotechnol Biol Med. 2007;3:63-74.

39. Wang Y, Moo YX, Chen C, Gunawan P, Xu R. Fast precipitation of uniform $\mathrm{CaCO}_{3}$ nanospheres and their transformation to hollow hydroxyapatite nanospheres. J Colloid Interface Sci. 2010;352(2):393-400.

40. Kamba, SA, Ismail M, Hussein-Al-Ali, SH, Ibrahim TAT, Zuki ABZ. In vitro delivery and controlled release of doxorubicin for targeting osteosarcoma bone cancer. Molecules. 2013;18:10580-10598.

41. Raju CL, Narasimhulu KV, Gopal NO, et al. Electron paramagnetic resonance, optical and infrared spectral studies on the marine mussel Arca burnesi shells. J Mol Struct. 2002;608(2-3):201-211.

42. Vongsavat V, Winotai P, Meejoo S. Phase transitions of natural corals monitored by ESR spectroscopy. Nucl Instrum Methods Phys Res B. 2006;2431:167-173.

43. Cheng B, Cai W, Yu J. DNA-mediated morphosynthesis of calcium carbonate particles. J Colloid Interface Sci. 2010;352(1):43-49.

44. Langer RS, Wise DL, editors. Medical Applications of Controlled Release, Applications and Evaluation. Vol. I and II. Boca Raton (FL): CRC Press; 1984.
45. Dash S, Murthy PN, Nath L, Chowdhury P. Kinetic modelling on drug release from controlled drug delivery systems. Acta Pol Pharm. 2010;673:217-223.

46. Narayanan D, Anitha A, Jayakumar R, Nair SV, Chennazhi KP. Synthesis, characterization and preliminary in vitro evaluation of PTH 1-34 loaded chitosan nanoparticles for osteoporosis. J Biomed Nanotechnol. 2012;8(1):98-106.

47. Eswaramoorthy R, Chang C, Wu S, Wang GJ, Chang JK, Ho ML. Sustained release of PTH (1-34) from PLGA microspheres suppresses osteoarthritis progression in rats. Acta Biomaterialia. 2012;8(2012): 2254-2262.

48. Kamba SA, Zakaria ZAB. Osteoblasts growth behaviour on bio-based calcium carbonate aragonite nanocrystal. Biomed Res Int. 2014; 215097.

49. Tran N, Webster TJ. Increased osteoblast functions in the presence of hydroxyapatite-coated iron oxide nanoparticles. Acta Biomaterialia. 2011;7(3):1298-1306.

50. Choi S-J, Oh J-M, Choy J-H. Toxicological effects of inorganic nanoparticles on human lung cancer A549 cells. J Inorganic Biochem. 2009;103(3):463-471. 


\section{Supplementary materials}

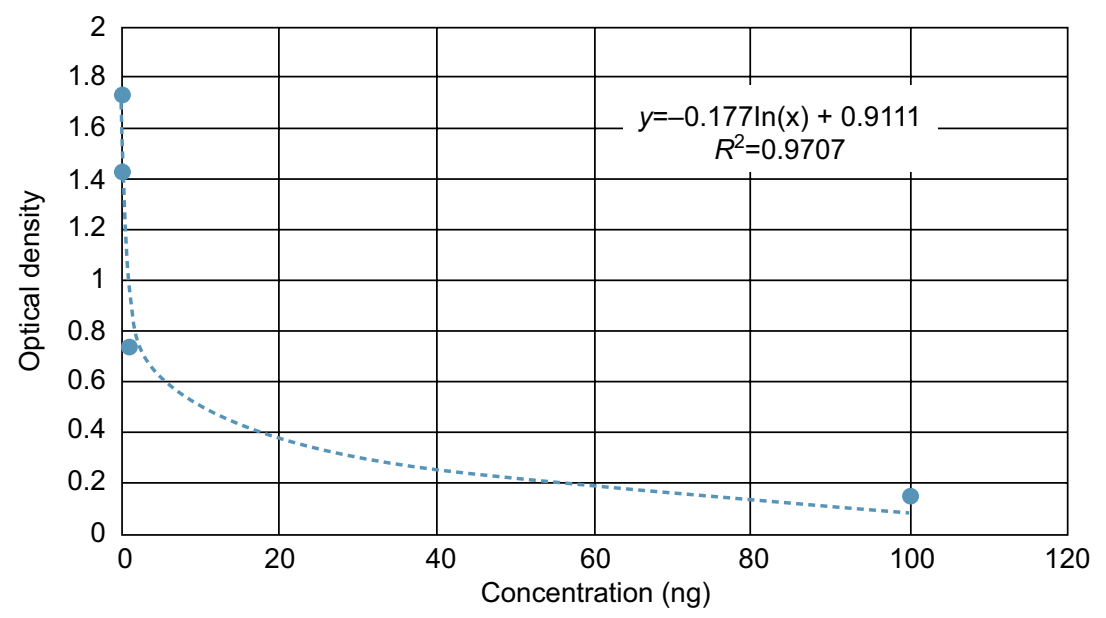

Figure SI PTH I-34 calibration curve.

Abbreviation: PTH I-34, parathyroid hormone I-34.

Table SI Cumulative PTH I-34 release from PTH-ANC at $\mathrm{pH} 7.5$ over $168 \mathrm{~h}$

\begin{tabular}{llll}
\hline Time (hour) & Quantity released (ng) & Percent released (\%) & Cumulative percentage (\%) \\
\hline 0 & 820.69 & 8.37 & 8.37 \\
0.5 & 195.00 & 1.99 & 10.36 \\
1 & 538.46 & 5.50 & 15.86 \\
3 & 833.82 & 8.51 & 24.37 \\
9 & 809.38 & 8.26 & 32.63 \\
24 & 911.95 & 9.31 & 41.93 \\
48 & 779.61 & 7.96 & 49.89 \\
72 & 448.89 & 4.58 & 54.47 \\
96 & 417.43 & 4.26 & 58.73 \\
120 & 398.45 & 4.07 & 62.79 \\
144 & 168.74 & 1.72 & 64.52 \\
168 & 485.94 & 4.96 & 69.47 \\
\hline
\end{tabular}

Abbreviations: PTH I-34, parathyroid hormone I-34; PTH-ANC, PTH I-34-loaded cockle shell aragonite calcium carbonate nanocrystals.

Nanotechnology, Science and Applications

\section{Publish your work in this journal}

Nanotechnology, Science and Applications is an international, peer-reviewed, open access journal that focuses on the science of nanotechnology in a wide range of industrial and academic applications. It is characterized by the rapid reporting across all sectors, including engineering, optics, bio-medicine, cosmetics, textiles, resource sustainability and science. Applied research into nano-materials,

\section{Dovepress}

particles, nano-structures and fabrication, diagnostics and analytics, drug delivery and toxicology constitute the primary direction of the journal. The manuscript management system is completely online and includes a very quick and fair peer-review system, which is all easy to use. Visit http://www.dovepress.com/ testimonials.php to read real quotes from published authors. 